\title{
Novos nomes, velhas práticas: o que há de diferente no Novo Mais Educação?
}

\author{
New names, old practices: what's different about New More \\ Education?
}

\section{Nuevos nombres, antiguas prácticas: ¿Qué tiene de diferente Nuevo Más Educación?}

\author{
Edna Cristina do Prado' \\ Universidade Federal de Alagoas, Programa de Pós-graduação em Educação, Professora \\ Associada. \\ https://orcid.org/0000-0001-8226-2466
}

\section{Eliene Brito Passos ${ }^{2}$}

Universidade Federal do Pará, Grupo de Pesquisa em Política, Gestão e Aualiação da Educação/UFPA/CNPq, Pesquisadora.

https://orcid.org/0000-0001-5624-8935

\section{Maria de Fátima Matos de Souza ${ }^{3}$}

Universidade Federal do Pará, Programa de Pós-graduação em Currículo e Gestão da Escola Básica, Professora Adjunta.

https://orcid.org/0000-0003-0214-8941

Resumo: A presente reflexão é fruto de estudos conjuntos desenvolvidos por dois grupos de pesquisa, da região Nordeste e Norte, respectivamente, e teve como objetivo analisar o que há de inovação no discurso oficial do Programa Novo Mais Educação (PNME), instituído por meio da Portaria Interministerial $n^{\circ}$ 1.144, de 10 de outubro de 2016, em substituição ao Programa Mais Educação. A abordagem metodológica adotada é de cunho qualitativo, desenvolvida por meio dos procedimentos da revisão bibliográfica e análise documental. Os trabalhos Cavaliere (2009), Dutra e Moll (2018), Moll (2012), Passos (2020), entre outros, deram suporte teórico à análise. Embora a proposta do "novo" programa seja melhorar a aprendizagem em Língua Portuguesa e Matemática no ensino fundamental com a ampliação da jornada escolar de crianças e adolescentes, mediante a complementação da carga horária com 5 ou 15 horas semanais, no turno e contraturno, as pesquisas já desenvolvidas no Brasil demonstram que

Pós-doutora em Educação pelo Instituto de Educação da Universidade de Lisboa, Portugal; Doutora em Educação pela Universidade Estadual de São Paulo.

Mestre em Educação pela Universidade Federal do Pará; Técnica em Educação pela Secretaria Estadual de Educação.

Pós-doutora em Educação pela Universidade Católica de Brasília; Doutora em Educação pela Universidade Estadual de São Paulo. 
a concepção de gestão adotada pelo PNME é de cunho gerencialista e está ancorada nas reformas que se encontram em curso no país desde a década de 1990, instalando nas escolas de educação básica a cultura da avaliação em larga escala cujos resultados assumem o epicentro dos debates.

Palavras-chave: Políticas públicas. Educação de Tempo Integral. Programa Novo Mais Educação.

Abstract: The present reflection is the result of joint studies developed by two research groups, from the Northeast and North regions, respectively, and aimed to analyze what is innovative in the official discourse of the New Program More Education (PNME), instituted through the Ordinance. Interministerial No. 1,144, of October 10, 2016, replacing the Mais Educação Program. The methodological approach adopted is of a qualitative nature, developed through the procedures of bibliographic review and document analysis. The works Cavaliere (2009), Dutra e Moll (2018), Moll (2012), Passos (2020), among others, gave theoretical support to the analysis. Although the proposal of the "new" program is to improve learning in Portuguese and Mathematics in elementary school with the extension of the school day of children and adolescents, by supplementing the workload with 5 or 15 hours per week, in the shift and in the evening, research already developed in Brazil shows that the management concept adopted by the PNME is of a managerial nature and is anchored in the reforms that have been underway in the country since the 1990s, installing in the schools of basic education the culture of large scale assessment whose results assume the epicenter of the debates.

Keywords: Public policy. Full-time education. New Program More Education.

Resumen: La presente reflexión es el resultado de estudios conjuntos desarrollados por dos grupos de investigación, de las regiones Nordeste y Norte, respectivamente, y cuyo objetivo es analizar qué es innovador en el discurso oficial del Nuevo Programa Más Educación (PNME), instituido a través de la Ordenanza. Interministerial No. 1.144, de 10 de octubre de 2016, en sustitución del Programa Mais Educação. El enfoque metodológico adoptado es de carácter cualitativo, desarrollado mediante los procedimientos de revisión bibliográfica y análisis documental. Las obras Cavaliere (2009), Dutra e Moll (2018), Moll (2012), Passos (2020), entre otros, dieron soporte teórico al análisis. Si bien la propuesta del "nuevo" programa es mejorar el aprendizaje de portugués y matemáticas en la escuela primaria con la extensión de la jornada escolar de niños y adolescentes, al complementar la carga de trabajo con 5 o 15 horas semanales, en el turno y en la tarde, Investigaciones ya desarrolladas en Brasil muestran que el concepto de gestión adoptado por el PNME es de carácter gerencial y está anclado en las reformas que se vienen realizando en el país desde la década de 1990, instalando en las escuelas de educación básica la cultura de evaluación a gran escala cuya Los resultados asumen el epicentro de los debates. Palabras clave: Políticas públicas. Educación a tiempo completo. Nuevo programa Más educación. 


\section{INTRODUÇÃO}

A presente reflexão é fruto de estudos conjuntos desenvolvidos por pesquisadores, mestrandos e doutorandos de dois grupos de pesquisa, um da região Nordeste e outro da região Norte do país. 0 grupo de pesquisa Gestão e Avaliação Educacional (GAE) e o grupo de pesquisa em Política, Gestão e Avaliação da Educação (PGAE) são certificados pelo Conselho Nacional de Desenvolvimento Científico e Tecnológico (CNPq) e, respectivamente, pelas Universidade Federal de Alagoas (UFAL) e Universidade Federal do Pará (UFPA).

0 objetivo do presente estudo consiste em analisar o que há de inovação no discurso oficial do Programa Novo Mais Educação (PNME), uma vez que inovar em educação também significa rever conceitos e concepções de aprendizagem, reavaliar o papel do educador e do educando em um processo ativo de troca de conhecimentos, e não somente no reforço de conteúdos que visam, sobretudo, elevar índices de aprendizagem. 0 referido programa foi instituído por meio da Portaria Interministerial $n^{\circ} 1.144$, de 10 de outubro de 2016 (em substituição ao Programa Mais Educação) a partir da revisão bibliográfica e da análise documental das teses, dissertações e artigos produzidos por pesquisadores e discentes dos programas de pós-graduação em Educação, no período de 2016 a 2019.

A educação integral consta como Meta 6 do atual Plano Nacional de Educação (PNE), o qual determina que até 2024 os estados e municípios com apoio da União deverão oferecer educação em tempo integral em, no mínimo, $50 \%$ das escolas públicas, de forma a atender, pelo menos, 25\% dos(as) alunos(as) da educação básica. Dessa forma, conhecer o percurso de sua implantação enquanto política pública e sua materialização nas escolas pela lente dos trabalhos já produzidos, torna-se de grande valia para futuras análises.

Para alcançar seu propósito, o texto está organizado em três seções, para além desta Introdução e das Considerações Finais. A primeira, intitulada A difícil superação: educação de tempo integral ou educação integral? apresenta, em linhas gerais, a trajetória da educação integral no Brasil até os dias atuais. Do velho ao "novo" é o título da seção seguinte que faz uma reflexão acerca das diferentes concepções de sociedade e de educação que influenciaram (e influenciam) as políticas públicas por meio de vários, pulverizados e efêmeros programas e projetos educacionais, dando destaque ao Programa Mais Educação (PME), de 2007 e ao seu substituto, o Programa Novo Mais Educação (PNME), de 2016. A terceira seção apresenta a análise dos dados coletados. 


\section{A DIFÍCIL SUPERAÇÃO: EDUCAÇÃO DE TEMPO INTEGRAL OU EDUCAÇÃO INTEGRAL?}

A educação integral não é uma temática nova, remonta à Paidéia grega, cuja educação era considerada um processo complexo e multifacetado que se prolongava por toda a vida. No Brasil, ganha notoriedade nas primeiras décadas do século XX com o Movimento dos Pioneiros da Educação Nova (1932), cuja bandeira de luta era a reconstrução educacional do país a partir de uma concepção de Educação Integral que ia de encontro à corrente da Ação Integralista Brasileira (AIB).

Os integralistas assumiram um papel moralizador da educação. De acordo com Cavaliere (2009, p. 249), para eles “[...] a educação integral envolvia o Estado, a família e a religião, posto em sintonia pela escola, numa intensiva ação educativa." Esse movimento tinha como lema a educação integral para um homem integral e, ainda de acordo com Cavaliere (2009), impunha valores tais como sacrificios, sofrimento, obediência aos superiores e até a morte por seus ideais moralizadores.

A educação integral no Brasil tem como principal percussor Anísio Teixeira. Para ele, a formação dos sujeitos deveria estar voltada à cooperação e participação, preconizando uma formação integral para além de uma educação escolar instrutiva. Anísio Teixeira defendia a ampliação das funções da escola, sendo esta ampliação, conforme Cavaliere (2009), um dos pilares de seu pensamento educacional, desenvolvido a partir de contato com John Dewey e Kilpatrick. Anísio Teixeira, após viagem aos Estados Unidos, passou a desenvolver uma concepção de educação escolar ampliada, a partir da qual propunha um novo modelo de homem, para uma nova sociedade, em que não apenas aprendesse os ensinamentos escolares, mas que fosse preparado para a vida e para as novas descobertas.

Nesse período, conhecido como Movimento do Pioneiros da Educação Nova, aconteciam as diversas reformas nos sistemas públicos estaduais de ensino, como, por exemplo, a de São Paulo com Sampaio Dória, em 1920, que dentre outras medidas, implementou a redução do ensino primário de quatro para dois anos, com o discurso de que "[...] se não tínhamos recursos para dar a todos a educação primária essencial, deveríamos simplificá-la até o máximo, até a pura e simples alfabetização e generalizá-la ao maior número" (CAVALIERE, 2003, p. 17) e a do Ceará com Lourenço Filho, em 1922, que tornava obrigatória a frequência escolar gratuita às crianças de 7 a 14 anos, promovendo um grande avanço no número de matrículas e na frequência escolar (SILVA, 2019). Essas reformas tiveram grande relevância para o processo de ampliação de vagas e até mesmo para a escolarização da maioria da população brasileira, que até então não tinha acesso à escola. Ainda de acordo com Cavaliere (2009), as reformas citadas não tiveram impacto na melhoria da qualidade do ensino, 
mas tiveram um papel importante no estabelecimento do consenso em torno da necessária ampliação do tempo de escolarização primária e da jornada diária dos alunos.

Foi com o desejo de inovação no campo educacional que Anísio Teixeira implantou, no estado da Bahia, na década de 50 do século XX, as Escolas Classe e as Escolas Parque 4 , representando uma das primeiras experiências efetivas de implantação de um sistema de ensino público voltado para uma educação integral, capaz de atender às necessidades educacionais dos filhos dos trabalhadores brasileiros, que ao longo da história sempre tiveram o acesso à escola negado.

Trinta anos depois, no primeiro mandato de Leonel Brizola (1983-1987), são criados, no Rio de Janeiro, os Centros Integrados de Educação Pública (CIEP), ${ }^{5}$ com Darcy Ribeiro à frente da Secretaria de Educação. Esses centros foram novas e ricas experiências de educação integral no país, mostrando a importância de o aluno permanecer um tempo maior na escola, com mais oportunidades de construção de conhecimentos significativos. 0 projeto educacional dos CIEP buscava assegurar educação integral em tempo integral, com duração diária de $9 \mathrm{~h}$ ( $8 \mathrm{~h}$ às $17 \mathrm{~h}$ ), oferecendo atividades curriculares, culturais, recreativas, estudos dirigidos e educação física, além de atendimento médico e odontológico (COELHO, 2009).

Com a promulgação da Constituição Federal de 1988 que responsabilizou o Estado e as famílias pelo acesso ao ensino com igualdade de condições e permanência com qualidade, começaram as discussões para a implementação de grandes reformulações no sistema educacional brasileiro, as quais só ganham concretude anos mais tarde com o disposto na Lei de Diretrizes e Bases da Educação Nacional (LDBEN) n 9394/96, que estabeleceu o sistema de ensino no Brasil já prevendo, em seu Art. 34, a ampliação progressiva do período de permanência dos alunos:

\footnotetext{
Art. 34. A jornada escolar no ensino fundamental incluirá pelo menos quatro horas de trabalho efetivo em sala de aula, sendo progressivamente ampliado o período de permanência na escola.

$\S \uparrow^{\circ}$ São ressalvados os casos do ensino noturno e das formas alternativas de organização autorizadas nesta Lei.

$\S 2^{\circ} 0$ ensino fundamental será ministrado progressivamente em tempo integral, a critério dos sistemas de ensino. (BRASIL, 1996, grifo nosso).
}

Nessa mesma perspectiva, a Lei $n^{\circ} 10.172$, de 9 de janeiro de 2001, aprovou o PNE para o decênio de 2001-2010 e trouxe as metas 21 e 22 para o ensino fundamental, que também

4 Mais amplas e com características arquitetônicas e pedagógicas inovadoras. Com destaque para o Centro Educacional Carneiro Ribeiro (CECR), estruturado em dois setores: o da instrução e o da educação.

5 Os Centros Integrados de Educação Pública (CIEP) foram criados no governo de Leonel Brizola, no Rio de Janeiro. Foram em torno de 500 prédios escolares com a finalidade de abrigar as escolas integrais. 
estabeleceram a ampliação progressiva da jornada escolar para atender preferencialmente as crianças oriundas de famílias de baixa renda.

\begin{abstract}
Meta 21: Ampliar, progressivamente a jornada escolar visando expandir a escola de tempo integral, que abranja um período de pelo menos sete horas diárias, com previsão de professores e funcionários em número suficiente. Meta 22: Prover, nas escolas de tempo integral, preferencialmente para as crianças das famílias de menor renda, no mínimo duas refeições, apoio nas tarefas escolares, a prática de esportes e atividades artísticas, nos moldes do Programa de Renda Mínima Associado a Ações Socioeducativas. (BRASIL, 2001, grifo nosso).
\end{abstract}

Somando-se a esse conjunto de leis, a Lei $n^{\circ} 11.494$, de 20 de junho de 2007 (BRASIL, 2007b) instituiu o Fundo de Manutenção e Desenvolvimento da Educação Básica e de Valorização dos Profissionais da Educação (Fundeb) e estabeleceu os critérios de financiamento para a jornada integral, passando o governo a destinar recursos aos estados e municípios que atendessem alunos em tempo integral em suas escolas.

Ainda no mesmo ano, o Decreto Federal n 6.094, de 24 de abril de 2007 (BRASIL, 2007a), instituiu o Plano de Metas Compromisso Todos pela Educação, dentro desse mesmo plano foi lançado pelo Governo Federal o Plano de Desenvolvimento da Educação (PDE), ao qual estão associados diversos programas, entre eles, o Programa Mais Educação (PME), considerado o indutor do tempo integral nas escolas da rede pública de ensino de todo o país.

A partir do exposto, as experiências de educação integral no Brasil apresentam concepções distintas que vão desde a busca por atendimento educacional integral a uma mera ampliação do tempo escolar, mas nenhuma experiência, ainda, foi capaz de implementar, em todo o território pátrio a educação integral, não passando de ações pontuais de estados e municípios, projetos e programas como já apontava Gadotti (2009, p. 9):

\footnotetext{
A educação integral não pode se constituir apenas num projeto especial de tempo integral, mas numa política para todos, entendendo-a como um princípio orientador do projeto eco-político-pedagógico de todas as escolas, - que implica conectividade, intersetorialidade, intertransculturalidade, intertransdisciplinariedade, sustentabilidade e informalidade. Enfim, educação integral é uma concepção geral de educação, que não se confunde com horário integral, o tempo integral ou jornada integral.
}

É necessário que se façam constantes reflexões acerca da história da educação brasileira, a fim de que as políticas educacionais sejam construídas e apropriadas aos que delas dependem, para não incorrerem em ações que beneficiam exclusivamente ao capital e que em nada acrescentam à educação do filho do trabalhador. De acordo com Mendes 
e Seemann (2016, p. 529), a política de ampliação da jornada escolar "[...] está muito mais voltada à melhoria dos indicadores educacionais do que propriamente à formação integral dos estudantes, revelando uma visão gerencialista e performativa no campo da educação escolar."

\section{DO UELHO AO “NOUO"}

0 Brasil vive um momento muito propenso ao debate entre as diferentes concepções e perspectivas de sociedade e de educação que já vêm de longa data. A década de 1990 trouxe várias implicações para o cenário educacional, dentre elas a promulgação da LDBEN/1996, originando a gestão gerencial e a democrática como modelos, por vezes, antagônicos. A gestão democrática é regimentada pela autonomia de decisões financeiras, pedagógicas e administrativas, conforme o princípio da gestão democrática instituído no art. 206 da Constituição Federal de 1988 (BRASIL, 1988). Já gerencialismo ${ }^{6}$ atua com o aumento do controle e da centralização das decisões, contrapondo-se aos processos de democratização da gestão nos sistemas educacionais públicos. Esse debate ganhou força em um momento em que havia uma urgência no enfrentamento das desigualdades sociais e no processo de exclusão que assolavam o país. As décadas passaram, mas essas desigualdades e a exclusão permaneceram de forma mais desumana que outrora.

A hodiernas tensões são reflexos das reformas da década de 1990 e permeiam todo o contexto social, principalmente o escolar, impondo a cada novo governo, mudanças estruturais no cenário educativo. Oliveira (2009a, p. 28) dialoga nessa direção quando diz que "[...] as políticas educacionais atuais se revestem cada vez mais de caráter social/assistencial e adotam como modelo de gestão a descentralização e a participação no nível local."

É importante lembrar que os princípios basilares da gestão democrática, presentes tanto na Constituição Federal/1988 quanto na LDB/1996, vêm sendo transformados por ações da gestão gerencial e, assim, contrapondo-se aos anseios de grande parte da população, que clama por uma educação pública, de qualidade socialmente referenciada e que esteja voltada para a formação integral do educando. De acordo com Silva, Silva e Santos (2016, p. 535):

As reformas oriundas da reestruturação do Estado viabilizaram mecanismos favoráveis à produtividade, à eficiência e à eficácia, justificados pela

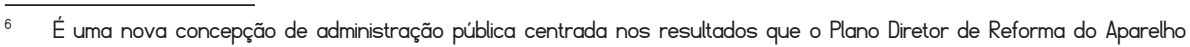
Estatal (PDRAE) denomina "gerencial", nos moldes empresariais do tipo toyotista, de qualidade total para a satisfação dos clientes-consumidores dos serviços públicos (SANTOS, 2010, p. 33). 
modernização e pelas novas roupagens que a sociedade incorpora em suas práticas culturais, sociais, políticas e educacionais.

Embora seja essa a compreensão atual do papel do Estado, torna-se pertinente um outro viés democrático, que se constrói com foco no desenvolvimento integral do aluno, conforme o garantido na Constituição Federal de 1988.

As mudanças ocasionadas pelas reformas educacionais geram inúmeros debates, principalmente quando envolvem os programas e projetos que chegam às escolas públicas e necessitam ser implementados pela gestão escolar. No entanto, pouco ou quase nada tem sido feito para que essas políticas resultem no efeito pretendido. Silva, Silva e Santos (2016, p. 536) afirmam que "[...] os objetivos pretendidos pelo Estado é que a comunidade local e a escolar assumam a responsabilização por criar estratégias para conseguir efetivar a educação com recursos (financeiros, humanos e materiais) mínimos."

Esses programas e projetos acabam por ser contraditórios ao que regulamenta a LDBEN/1996, que estabelece a gestão democrática enquanto prática a ser vivenciada nas escolas públicas. Em sentido oposto, o que essas políticas educacionais, como por exemplo a Prova Brasil, vêm desencadeando é uma competição entre escolas, em detrimento das práticas solidárias, coletivas, inclusivas e propícias ao pleno desenvolvimento do educando. Para Oliveira (2009b, p. 239):

\begin{abstract}
As politicas educacionais precisam, então, ser pensadas, implementadas e avaliadas com base na ação de um estado moderno que desenvolve um projeto nacional em consonância com os interesses da maioria da população. A inclusão social das camadas menos favorecidas aponta para a necessidade de constituição de um estado social que atua por meio de políticas públicas, sociais e educacionais que favoreçam os processos de emancipação desejados. Os sistemas de ensino, as escolas, os gestores, os professores, os alunos e a comunidade escolar em geral são agentes fundamentais desse processo, por isso, precisam ser envolvidos no estabelecimento de programas, projetos e ações que afetam a produção do trabalho escolar, uma vez que devem ser concebidos como agentes transformadores da própria realidade em que atuam.
\end{abstract}

As políticas públicas voltadas para as necessidades e anseios da maioria da população necessitam ser fruto de um amplo debate, para que não incorram em desperdício dos parcos recursos que ainda são destinados à sua execução. Além dos aspectos contraditórios que marcam as políticas públicas, levando as escolas à competição por melhores posições em ranqueamentos, ocorre ainda a quase inexistência de recursos para a implementação dos programas e projetos oriundos do Governo Federal e ou estadual. 
Entre tais programas, merece destaque o Programa Mais Educação (PME), criado pelo governo federal em 2007 e com ações executadas até final de 2015. 0 programa constituía-se como uma estratégia de política pública de ação indutora para educação de tempo integral, com foco na ampliação da jornada escolar nas instituições de ensino e na reorganização curricular, por meio de um processo pedagógico que conectava áreas do saber à cidadania, ao meio ambiente, aos direitos humanos, à cultura, às artes, à saúde e à educação econômica. Conforme o documento "Mais Educação: passo a passo" (BRASIL, 2013), a "jornada ampliada" era organizada em oficinas, cujas atividades aconteciam no contraturno, por meio de dez macrocampos, assim denominados: Acompanhamento pedagógico; Meio ambiente, Esporte e lazer; Direitos humanos em educação, Cultura e artes, Cultura digital, Promoção da saúde; Educomunicação, Investigação no campo das ciências e natureza e Educação econômica, que juntos seriam responsáveis pelo alcance dos objetivos previstos no Decreto $n^{\circ} 7.083 / 2010$ :

I - formular política nacional de educação básica em tempo integral;

\| - promover diálogo entre os conteúdos escolares e os saberes locais;

III - favorecer a convivência entre professores, alunos e suas comunidades;

IV - disseminar as experiências das escolas que desenvolvem atividades de educação integral; e

V - convergir políticas e programas de saúde, cultura, esporte, direitos humanos, educação ambiental, divulgação cientifica, enfrentamento da violência contra crianças e adolescentes, integração entre escola e comunidade, para o desenvolvimento do projeto político-pedagógico de educação integral. (BRASIL, 2010, art. $3^{\circ}$ ).

Cumpre ressaltar que o Programa Mais Educação, foi um dos programas com maior volume de recursos destinados à implementação de suas ações, com o envolvimento de diferentes setores do governo ${ }^{7}$ para o alcance de seus objetivos (PASSOS, 2020). Mesmo assim, de acordo com pesquisa feita pelo grupo empresarial Fundação Itaú Social e pelo Grupo Banco Mundial, em 2015, o PME não alcançou suas metas e propósitos, sendo extinto oito aos após sua criação. Em seu lugar foi proposto um novo programa, que em seu próprio nome trazia uma contradição: o novo (programa de 2016) e o velho (nomenclatura do extinto em 2015).

0 Programa Novo Mais Educação (PNME) foi criado por meio da Portaria Interministerial $n^{\circ} 1.144$, de 10 de outubro de 2016, com objetivos muito claros quanto à extensão do tempo escolar e à melhoria da aprendizagem dos alunos com apenas dois componentes curriculares, considerados como básicos: Português e Matemática. Conforme a portaria:

\footnotetext{
A Portaria Interministerial n. 17/2007, que instituiu o PME, foi lançado sob a égide do MEC, e também assinada pelos ministros do Desenvolvimento Social e Combate à Fome, bem como os do Esporte e da Cultura, o que caracteriza a intersetorialidade na criação do programa (BRASIL, 2007c).
} 
Art. $1^{\circ}$ Fica instituido o Programa Novo Mais Educação, com o objetivo de melhorar a aprendizagem em língua portuguesa e matemática no ensino fundamental, por meio da ampliação da jornada escolar de crianças e adolescentes, mediante a complementação da carga horária de cinco ou quinze horas semanais no turno e contraturno escolar.

Parágrafo único. 0 Programa será implementado por meio da realização de acompanhamento pedagógico em língua portuguesa e matemática e do desenvolvimento de atividades nos campos de artes, cultura, esporte e lazer, impulsionando a melhoria do desempenho educacional. (BRASIL, 2016a, grifo nosso).

A implantação do PNME nos municípios já ocorreu, em grande parte, no final de 2016. Muitas escolas foram orientadas a utilizar os recursos reprogramados do ano anterior em atividades pedagógicas adequadas ao formato do PNME. No entanto, somente no final de 2017 é que, de fato, as escolas puderam fazer adesão ao programa diretamente no sistema Programa Dinheiro Direto na Escola (PDDE) interativo. ${ }^{8}$ Vale ressaltar que os critérios para contemplação eram: escolas com IDEB inferior a 4,4 para os anos iniciais do ensino fundamental e inferior a 3,0 para os anos finais; como também ter no mínimo $50 \%$ dos alunos matriculados no Programa Bolsa Família, conforme Resolução n 17, de 22 de dezembro de 2017.

Todas as escolas contempladas pelo PNME apresentavam baixos índices de aprendizagem, e o alunado era composto por no mínimo 50\% de alunos inscritos no Programa Bolsa Família, indicando que grande parte deles se encontrava em situação de vulnerabilidade social.

Com a substituição do PME pelo PNME, houve uma grande redução no número de escolas contempladas, em função dos critérios estabelecidos pela Resolução de $n^{\circ} 17 / 2017$.

\footnotetext{
1 - escolas que receberam recursos na conta PDDE Educação Integral entre 2014 e 2016.

\| - escolas que apresentam Índice de Nível Socioeconômico baixo ou muito baixo segundo a classificação do Instituto Nacional de Estudos e Pesquisas Educacionais Anísio Teixeira (INEP);

III - escolas que obtiveram baixo desempenho no Índice de Desenvolvimento da Educação Básica (IDEB). (BRASLL, 2017a).
} 
No que tange aos recursos destinados a programas educacionais, é pertinente lembrar que quando Programa Novo Mais Educação foi instituído ocorreu uma drástica redução nos recursos financeiros em relação ao programa anterior (PME), transferindo para a gestão da escola o desafio de implementá-lo com um orçamento limitado basicamente ao pagamento do auxílio dos mediadores e facilitadores.

Ainda de acordo com o Relatório do $3^{\circ}$ ciclo de monitoramento das metas do PNE (2014-2024), que analisa a meta 6, a região Norte foi a que apresentou os percentuais mais baixos, tanto de alunos quanto de escolas que ofertam a Educação de Tempo Integral, o que contribui para que a referida meta não seja atingida até final da vigência do Plano, em 2024 (INSTITUTO NACIONAL DE ESTUDOS E PESQUISAS EDUCACIONAIS ANÍSIO TEIXEIRA, 2020).

0 Estado cria leis, programas e projetos, no entanto, tem assumido nas últimas décadas, o papel de mero fiscalizador, deixando para a gestão escolar a responsabilidade de conduzir o processo aliada ao protagonismo dos pais, dos alunos, dos professores e da comunidade escolar em geral que, por meio de seus órgãos colegiados, acaba por assumir maior parte da responsabilidade pelos resultados, principalmente quando são negativos.

\section{QUE DIZEM OS DADOS}

Uma consulta sistemática aos bancos digitais de acesso aberto do país, considerando o período de 2016 a 2019 como recorte temporal, permite constatar que, embora recente, o PNME já possui uma considerável produção tendo vários de seus aspectos abordados como objetos de estudo.

Os Quadros 1 e 2 apresentam o resultado do levantamento realizado nos bancos de dados digitais de acesso livre Scientific Electronic Library Online (SciELO) Brasil; Google Acadêmico; Directory of Open Access Journals (DOAJ) Brasil e Biblioteca Digital de Teses e Dissertações do Instituto Brasileiro de Informação em Ciência e Tecnologia (IBICT), a partir dos descritores: "educação integral"; "tempo integral"; "Programa Mais Educação"; "Programa Novo Mais Educação": 
Quadro 1 - Trabalhos de conclusão de curso acerca do Programa Novo Mais Educação (2016-2019)

\begin{tabular}{|c|c|c|c|c|}
\hline Tipo & Universidade/Ano & Autor & Título da Pesquisa & Objetivo da Pesquisa \\
\hline TCC & $\begin{array}{l}\text { Universidade } \\
\text { Federal do Pará- } \\
\text { UFPA/2018 }\end{array}$ & $\begin{array}{l}\text { Larissa } \\
\text { Pantoja da } \\
\text { Gama }\end{array}$ & $\begin{array}{l}\text { Programa Novo Mais } \\
\text { Educação: Um Estudo de } \\
\text { Sua Implementação em } \\
\text { uma escola o campo em } \\
\text { Castanhal/PA }\end{array}$ & $\begin{array}{l}\text { Conhecer como vem se dando } \\
\text { a implementação do PNME na } \\
\text { escola "Roberto Remigi" }\end{array}$ \\
\hline Dissertação & $\begin{array}{l}\text { Universidade } \\
\text { Estadual Paulista } \\
\text { "Júlio de Mesquita } \\
\text { Filho"-UNESP/2018 }\end{array}$ & $\begin{array}{l}\text { Gabriela } \\
\text { Freitas } \\
\text { Saquelli }\end{array}$ & $\begin{array}{l}\text { Programa Mais Edu- } \\
\text { cação e o Novo Mais } \\
\text { Educação: Permanên- } \\
\text { cias e Rupturas }\end{array}$ & $\begin{array}{l}\text { Analisar os desenhos exis- } \\
\text { tentes nos Programas Mais } \\
\text { Educação e Novo Mais Educa- } \\
\text { ção, com foco na concepção } \\
\text { de Educação/ Tempo Integral, } \\
\text { nesse sentido as permanências } \\
\text { e rupturas políticas entre eles }\end{array}$ \\
\hline Tese & \begin{tabular}{|l} 
Universidade \\
Federal do Rio \\
Grande do Sul/2018
\end{tabular} & $\begin{array}{l}\text { Vagner } \\
\text { Peruzzo }\end{array}$ & \begin{tabular}{|l} 
Educação [Em Tempo] \\
Integral \\
A Contribuição do Pro- \\
grama Mais Educação \\
- PME à Comunidade \\
Escolar em um município \\
da Serra Gaúcha/RS \\
\end{tabular} & $\begin{array}{l}\text { Investigar as contribuições do } \\
\text { Programa Mais Educação (PME) } \\
\text { criado no segundo mandato do } \\
\text { Presidente Lula, em } 2007 .\end{array}$ \\
\hline Tese & $\begin{array}{l}\text { Universidade } \\
\text { Federal de Minas } \\
\text { Gerais/2017 }\end{array}$ & $\begin{array}{l}\text { Patrícia } \\
\text { Moulin } \\
\text { Mendonça }\end{array}$ & $\begin{array}{l}0 \text { Direito à Educação } \\
\text { em questão: as tensões } \\
\text { e disputas no interior } \\
\text { do Programa Mais } \\
\text { Educação }\end{array}$ & $\begin{array}{l}\text { Identificar as disputas e as } \\
\text { tensões em torno do direito à } \\
\text { educação integral no Brasil, e, } \\
\text { mais especificamente, em torno } \\
\text { do Programa Mais Educação }\end{array}$ \\
\hline Dissertação & $\begin{array}{l}\text { Universidade } \\
\text { Federal de } \\
\text { Goiás/2018 }\end{array}$ & $\begin{array}{l}\text { Deuzeni } \\
\text { Gomes da } \\
\text { Silva }\end{array}$ & $\begin{array}{l}\text { Educação Integral: uma } \\
\text { Análise dos Programas } \\
\text { Mais Educação e Novo } \\
\text { Mais Educação no } \\
\text { Município de Bela Vista } \\
\text { de Goiás }\end{array}$ & $\begin{array}{l}\text { Analisar a proposta de edu- } \\
\text { cação integral em curso no } \\
\text { município de Bela Vista de Goiás, } \\
\text { por meio da implementação } \\
\text { do PME e PNME em uma das } \\
\text { unidades escolares da rede } \\
\text { municipal de ensino }\end{array}$ \\
\hline Dissertação & $\begin{array}{l}\text { Universidade } \\
\text { Federal do Pará- } \\
\text { UFPA/2018 }\end{array}$ & $\begin{array}{l}\text { Cintia Aurora } \\
\text { Quaresma } \\
\text { Cardoso }\end{array}$ & $\begin{array}{l}\text { Programa Novo Mais } \\
\text { Educação (2016) e sua } \\
\text { Concepção de Educação } \\
\text { em Tempo Integral } \\
\end{array}$ & $\begin{array}{l}\text { Analisar os princípios basilares } \\
\text { do Programa Novo Mais Educa- } \\
\text { ção (PNME) e a sua concepção } \\
\text { de educação em tempo integral }\end{array}$ \\
\hline Tese & $\begin{array}{l}\text { Universidade } \\
\text { Federal da Bahia- } \\
\text { UFBA/2019 }\end{array}$ & $\begin{array}{l}\text { João Paulo } \\
\text { Jonas de } \\
\text { Almeida }\end{array}$ & $\begin{array}{l}\text { Programa (Novo) Mais } \\
\text { Educação: Estratégia } \\
\text { da Governamentalidade } \\
\text { Neoliberal para a Con- } \\
\text { dução das Condutas de } \\
\text { Todos e de Cada Um } \\
\end{array}$ & $\begin{array}{l}\text { Realizar uma análise do dis- } \\
\text { curso produzido pelo Programa } \\
\text { (Novo) Mais Educação (PNME). }\end{array}$ \\
\hline
\end{tabular}

Fonte: Passos (2020, p. 21). 
Em praticamente dois anos (considerando que adesão ao PNME de fato ocorre em 2017) já foram produzidas três dissertações de mestrado, três teses de doutorado e um trabalho de conclusão de curso de graduação em várias regiões do país.

Além de teses, dissertações e trabalhos de conclusão de curso, foi realizada uma consulta sobre os artigos acadêmico-científicos publicados nos bancos digitais de acesso livre: periódicos da Coordenação de Aperfeiçoamento de Pessoal de Nivel Superior (CAPES) e Google Acadêmico, com os descritores "Programa Mais Educação" e "Programa Novo Mais Educação":

Quadro 2 - Artigos científicos sobre o Programa Novo Mais Educação (2016-2019)

\begin{tabular}{|l|l|c|}
\hline \multicolumn{1}{|c|}{ Título } & \multicolumn{1}{|c|}{ Autorles) } & \multicolumn{1}{|c|}{ Ano } \\
\hline $\begin{array}{l}\text { Reverberaçães do programa novo mais educação } \\
\text { (PNME) para a formação de identidades de estudantes } \\
\text { de escolas públicas em Castanhal-PA }\end{array}$ & Evilly Vieira de Sousa; Madison Rocha Ribeiro & 2019 \\
\hline $\begin{array}{l}\text { O conceito de avaliação da aprendizagem no Programa } \\
\text { Novo Mais Educação }\end{array}$ & $\begin{array}{l}\text { Heike Schmitz; Beatriz Noia Souza; José Luis } \\
\text { Monteiro da Conceição }\end{array}$ & 2019 \\
\hline $\begin{array}{l}\text { A formação de professores em educação matemática } \\
\text { no programa novo mais educação (PNME) no estado do } \\
\text { Tocantins: pontos e contrapontos }\end{array}$ & $\begin{array}{l}\text { Dailson Evangelista Costa; Mônica Suelen } \\
\text { Ferreira de Moraes; Vanessa Tavares Pimen- } \\
\text { tel; Roseli Bitzcof de Moura }\end{array}$ & 2019 \\
\hline $\begin{array}{l}\text { O Mais Educação na América Latina: legados a infâncias } \\
\text { e juventudes pobres }\end{array}$ & $\begin{array}{l}\text { Levindo Diniz Carvalhol; Bárbara Ramalhol; } \\
\text { Kildo Adevair dos Santos }\end{array}$ & 2019 \\
\hline $\begin{array}{l}\text { Educação integral elm) tempo integral, o Programa } \\
\text { "Novo" Mais Educação e sua concepção de formação } \\
\text { humana }\end{array}$ & $\begin{array}{l}\text { Saraa César Mól; Cosme Leonardo Almeida } \\
\text { Maciel; Flávia Silva Martins }\end{array}$ & 2017 \\
\hline
\end{tabular}

Fonte: Passos (2020, p. 22).

As produções elencadas nos quadros 1 e 2 trazem informações relevantes para o processo de compreensão da temática em tela, com o predomínio de análises comparativas entre o PME e o PNME. Seus resultados convergem para que se compreenda a concepção de cada um desses programas e sua importância para o desenvolvimento de uma política de educação integral em tempo integral nas escolas brasileiras.

A análise dos documentos do governo federal mostrou-se uma constante em todos os trabalhos analisados, com destaque para os referidos textos oficiais: 
Quadro 3 - Documentos oficiais acerca do PNME mais recorrentes nas produções sobre o tema

\begin{tabular}{|l|l|}
\hline \multicolumn{1}{|c|}{ Documentos } & \multicolumn{1}{c|}{ Referências } \\
\hline $\begin{array}{l}\text { 1- Portaria } n^{\circ} 1.144, \text { de } \\
\text { 10/10/2016 }\end{array}$ & $\begin{array}{l}\text { Portaria que institui o PNME: busca melhorar a aprendizagem em língua portugue- } \\
\text { sa e matemática no ensino fundamental, com a ampliação da jornada escolar de } \\
\text { crianças e adolescentes, mediante a complementação da carga horária de cinco ou } \\
\text { quinze horas semanais no turno ou no contraturno escolar. }\end{array}$ \\
\hline $\begin{array}{l}2 \text { - Resolução } n^{\circ} 17, \text { de } \\
22 / 12 / 2017\end{array}$ & $\begin{array}{l}\text { Resolução que destina recursos financeiros para cobertura de despesas de } \\
\text { custeio, nos moldes operacionais e regulamentares do Programa Dinheiro Direto na } \\
\text { Escola-PDDE a escolas públicas municipais, estaduais e do Distrito Federal. }\end{array}$ \\
\hline $\begin{array}{l}\text { 3- Documento Orienta- } \\
\text { dor-Adesão Versão 1, de } \\
\text { outubro de 2016 }\end{array}$ & $\begin{array}{l}\text { Versão I (2016), apresenta orientações para as secretarias de educação seleciona- } \\
\text { rem as escolas que farão adesão ao PNME. }\end{array}$ \\
\hline $\begin{array}{l}\text { c- Caderno de Orienta- } \\
\text { ções Pedagógicas-2017 }\end{array}$ & $\begin{array}{l}\text { Versão I (2017), apresenta orientações para serem realizadas por cada escola aderi- } \\
\text { da ao PNME, cuja finalidade é ser um documento orientador para o desenvolvimento } \\
\text { do trabalho pedagógico da escola. }\end{array}$ \\
\hline
\end{tabular}

Fonte: Passos (2020, p. 27).

Quanto ao que há de "novo" no Programa Novo Mais Educação (2016) em comparação ao seu antecessor, os dados coletados permitem afirmar que houve mudanças significativas em sua concepção. Enquanto o PME visava fomentar a educação integral de crianças, adolescentes e jovens, por meio de apoio a atividades socioeducativas no contraturno, o PNME tem por objetivo apenas a melhoraria a aprendizagem dos alunos do ensino fundamental em Português e Matemática, para efeitos de elevação dos dados do ĺndice de Desenvolvimento da Educação Básica (IDEB), sem qualquer preocupação com a formação integral do aluno. Além do que, segundo Cardoso (2016) ao limitar as atividades das escolas à leitura e matemática, acabam sendo ignorados aspectos fundamentais da cidadania, como, por exemplo, ética, responsabilidade social, direitos humanos, meio ambiente e dimensões afetivas e físicas, essenciais para formação plena do sujeito. A comprovação dessa única preocupação com os resultados pode ser constatada na perversa novidade do programa: a redução substancial dos recursos a ele destinados, transferindo a responsabilidade pelo sucesso das ações aos executores locais que deveriam fazer o mesmo (e por vezes mais), com o menos.

A já fragilizada concepção de educação integral do Programa Mais Educação (2007) tornou-se ainda mais esmaecida, uma vez que tem sido incapaz de atender às necessidades dos alunos e escolas atendidos pelo programa, que, desde sua formulação, não pensou nas especificidade desses sujeitos, pois de acordo com Arroyo (1988), a primeira coisa a ser refletida deveria ser "[...] em quem se pensa quando se propõe uma escola de tempo integral", isto porque a escola pública de hoje certamente não recebe os filhos da elite brasileira. Portanto, ao pensar apenas na ampliação da jornada diária sem a construção de 
uma proposta pedagógica que vá ao encontro dos anseios e necessidades dos filhos dos trabalhadores é, no mínimo, um engodo.

Os programas que chegam às instituições escolares da rede pública de ensino, principalmente de educação integral, acabam por demandar uma infraestrutura, física e humana, de que muitas escolas não dispõem, o que exige do poder público um cuidado maior com a deliberação dessas políticas para de fato serem viáveis e estarem de acordo com a realidade para a qual foram destinadas. É fato que, ao menos no plano discursivo, esses programas trazem a tentativa de melhorar a aprendizagem, mas pecam ao atribuir o fracasso escolar, exclusivamente, ao tempo de permanência do aluno na escola. Para Arroyo (2012, p. 35), esses programas têm como um dos seus significados políticos "....] serem tentativas de respostas públicas a movimentos sociais que já vem reivindicando ao longo da história vivências de tempos-espaços mais dignos." Mas, vivência mais digna não se reduz à ampliação de horas. Em certos casos, permanecer mais horas em um ambiente insalubre e com tempo ocioso será, com certeza, mais prejudicial.

Os alunos precisam de fato (e de direito) usufruir de conhecimentos que estão presentes não somente nas disciplinas curriculares e nos dois componentes tidos como essenciais pelo PNME (língua portuguesa e matemática), mas também dos saberes oriundos das artes, do esporte e da cultura. Moll (2012) afirma que as crianças de camadas médias, como podem pagar, já fazem essas atividades no contraturno, ou seja, já usufruem de uma jornada ampliada, o que não tem acontecido com a maioria das crianças que é matriculada na rede pública de ensino, que depende, exclusivamente, da oferta de atividades diversificadas pelo poder público. Oferta esta que, como apontando nos trabalhos aqui analisados, nem sempre é diversificada e, o que é pior, muitas vezes nem acontecem com regularidade.

Mais do que a busca por uma educação integral, o PNME mostra-se como uma mera tentativa de atender à política de ampliação do tempo escolar já estipulada no anterior Plano Nacional de Educação (PNE) 2001-2010, que propunha em sua Meta II (sobre a educação fundamental) um modelo de educação em turno integral. Desde o início deste século, o intuito de vários governantes tem sido universalizar o ensino e diminuir as taxas de retenção, ainda que por meios duvidosos quanto à sua eficiência, eficácia e efetividade.

A almejada ampliação da jornada não atingiu níveis significativos de matrículas na educação integral como previa o PNE 2001-2010, nem os números atuais têm atendido às metas do PNE 2014-2024. Esse último, o PNE 2014-2024, estabelece como meta a oferta de educação em tempo integral para, no mínimo, $50 \%$ das escolas públicas e o atendimento de, ao menos, $25 \%$ dos estudantes de educação básica do Brasil, mas tais percentuais ainda se mostram muito distantes e, para muitos, inatingiveis no prazo estipulado diante dos parcos recursos (financeiro, técnico-pedagógico, infraestrutura, formação docente, currículo) investidos (PASSOS, 2020). 
Entretanto, os dados analisados, em especial nos estudos comparativos entre os dois programas, indicam que o PME (2007) trouxe importantes avanços à educação nacional, corroborando a afirmação de que:

\begin{abstract}
0 Programa Mais Educação, por sua vez, constitui a estratégia indutora que, no âmbito pedagógico e curricular, colabora para o exercício cotidiano da progressiva expansão e reorganização do tempo escolar, assim como da progressiva inclusão de estudantes na possibilidade de processos educativos escolares ampliados e ressignificados. 0 Programa Mais Educação colabora no processo de construção de uma agenda escolar cotidiana para a efetiva consolidação da educação integral. (MOLL, 2012, p. 138).
\end{abstract}

Mas a possiblidade de processos educativos ressignificados e ampliados não foi considerada pelo o PNME. Enquanto o PME (2007) apresentava um foco na formação integral dos alunos, mediante atividades desenvolvidas a partir das oficinas realizadas na escola ou em articulação com espaços diversos, o PNME (2016) tem como objetivo melhorar a aprendizagem em Língua Portuguesa e Matemática com a ampliação da jornada em cinco ou quinze horas:

\footnotetext{
No Programa Novo Mais Educação o acompanhamento pedagógico dos estudantes ganha centralidade como estratégia para enfrentamento das dificuldades de aprendizagem e superação do fracasso escolar. Por isso, as ações propostas visam a melhoria da aprendizagem em Matemática e Língua Portuguesa, por meio da intervenção direta sobre o processo de alfabetização e letramento nessas duas áreas. (BRASIL, 2017b, p. 20).
}

Os objetivos do programa são bastante claros quando o documento diz que a melhoria da aprendizagem se dará por meio da intervenção direta sobre o processo de alfabetização em duas áreas do conhecimento. Todavia, para superar o fracasso escolar, são necessárias ações efetivas que estão para além da intervenção direta somente em Português e Matemática, como ressalta o documento acima. 0 foco principal da aprendizagem do educando não pode ser somente as disciplinas que atendem ao IDEB, pois dessa forma a escola corre o risco de esquecer tudo que já foi produzido historicamente (SAQUELLI, 2018).

As escolas necessitam de investimentos na infraestrutura, na formação dos servidores, a gestão das escolas necessita de condições para trabalhar, ou seja, é necessário mais investimento por parte do poder público para que as ações possam ser desenvolvidas de maneira satisfatória e que os alunos possam ser acolhidos em espaços dignos e propícios ao desenvolvimento pleno. De modo que, investir na ampliação do tempo de permanência do aluno na escola, oferecendo apenas mais português e matemática não 
garante o pleno desenvolvimento do educando. Portanto, o "novo programa" que transmite a ideia de inovação, não passa da velha política educacional, retrógada, que vigora há décadas e que não tem funcionado (PERUZZO, 2018).

A centralização em apenas duas disciplinas, como faz o PNME, acarreta - empobrecimento das demais áreas do conhecimento que também devem compor o desenvolvimento pleno do aluno. Para Mendonça (2017, p. 160), "[...] o Novo Mais Educação é focado na concepção de ensino e aprendizagem de alguns conteúdos, não de todos, numa concepção de educação integral focada na ampliação da jornada escolar e não da formação integral do sujeito." Mól, Maciel e Martins (2017, p.10) também concluíram em seus estudos que a "...] finalidade formativa do PNME não está voltada para uma formação humana multidimensional, mas sim para uma formação escolar que possibilite o alcance de metas estabelecidas pelas avaliações externas."

Neste sentido, focar somente no ler, escrever e contar demonstra uma visão reducionista e fragmentada de educação, em que importa apenas avaliar e quantificar o que o aluno conseguiu aprender ou não, não o reconhecendo como um todo, estando, assim, distante dos ideais de educação integral:

\footnotetext{
As finalidades do novo Programa mostram a preocupação com as questões referentes à alfabetização, letramento, abandono, evasão, distorção idade/ ano, resultados de aprendizagem e ampliação do período de permanência dos alunos na escola, o que demonstra uma política de governo focada numa formação que ofereça condições aos alunos para alcançarem bom desempenho educacional. (CARDOSO, 2018, p. 97).
}

Diante do exposto, os trabalhos analisados explicitam que se faz necessária uma política pública que proporcione condições reais para a implementação de uma educação integral nas escolas públicas brasileiras de educação básica, nas quais as experiências culturais, digitais, inovadoras, desportivas e de lazer sejam concebidas como primordiais (não meros apêndices de preenchimento de carga-horária) para a construção de uma "educação integral em tempo integral" e que represente, verdadeiramente, o resgate da cidadania, o que o PNME, mesmo atingindo a todos os seus objetivos, jamais será capaz de fazer, pois como afirma Moll (2018), o PNME vem sendo uma ação do Governo Federal, restrita ao reforço escolar e com foco nas avaliações de larga escala. 


\section{CONSIDERAÇÕES FINAIS}

Diante da complexidade que envolve a temática em tela, não foi pretensão deste estudo ter encontrado todas as respostas para os questionamentos feitos sobre o PNME, quer seja por parte dos pesquisadores que o tomam como objeto de estudo, quer pelos docentes que seguem suas orientações no chão da escola. Mas, espera-se que ao longo deste percurso reflexivo, as questões suscitadas possam abrir caminhos a outras e importantes compreensões.

0 PNME é programa que se se anuncia como novo, mas que apenas desestruturou uma tentativa plausível de política de educação de tempo integral, constituindo-se mais um mero reforço escolar, muitas vezes ofertado no mesmo horário das aulas do aluno. No lugar de inovação, trouxe um retrocesso para muitas escolas que dele participam.

Após análise dos dados coletados, constata-se que o Programa Novo Mais Educação desenvolvido nas escolas brasileiras, embora tenha contribuído de forma mais ou menos significativa, dependendo da localidade, para a melhoria dos índices de aprovação e reprovação, não trouxe as inovações anunciadas, não só por se apresentar ineficaz, desde sua concepção (mais gerencialista e excludente que seu antecessor), mas por sofrer descaracterização de sua já fragilizada proposta ao se deparar com o sucateamento da educação pública nacional.

0 PNME objetiva, na verdade, melhorar os resultados dos alunos em Língua Portuguesa e Matemática no ensino fundamental, por meio da ampliação da jornada escolar. No entanto, diante dos parcos recursos a ele destinados, nem isto tem sido capaz de alcançar de forma satisfatória. 0 programa rompe com qualquer preocupação com a formação mais geral do aluno, tanto é que em seu documento normativo (Resolução FNDE/ CD n 5, de 25/10/2016) não há qualquer referência à "Educação Integral". No Caderno de Orientações Pedagógicas (2018) constam apenas três pequenas referências a ela quando são apresentados os requisitos necessários para a atuação de coordenadores, mediadores e facilitadores, afirmando que esses devem ter experiência em Educação Integral, como se a experiência desses profissionais fosse suficiente para o seu desenvolvimento, dentro de uma proposta que está preocupada apenas com dois componentes curriculares: Português e Matemática.

Sem um aporte de recursos regulares e suficientes à educação, não se concebe uma educação de qualidade socialmente referenciada, seja ela integral, de tempo integral ou de tempo parcial. Sem investimentos em infraestrutura, recursos materiais, pedagógicos, qualificação e valorização dos profissionais da escola, a educação integral mostra-se, ainda, muito distante das camadas mais vulneráreis e dependentes do Estado. 
A análise dos resultados permitiu identificar, também, a concepção de gestão gerencialista que norteia o programa, ancorada nas reformas que vêm acontecendo no país desde a década de 1990, que por meio de diversos, pulverizados e descontinuados programas e projetos implantados nas escolas, buscam manter o controle dos processos educativos, os quais amargam baixos indicadores de eficiência, eficácia efetividade. 0 PNME está pautado no controle e na centralização por meio de testes padronizados que verificam apenas a dimensão cognitiva alcançada pelo aluno, ignorando com isso a formação humana multidimensional e o contexto sócio-histórico de formação dos sujeitos.

0 PNME não apresentou inovações capazes de superar o Programa Mais Educação que o antecedeu, configurando-se apenas como um mero reforço escolar. Portanto, não se coloca enquanto uma política indutora de educação integral no país, constituindo-se apenas como uma estratégia de melhoria da aprendizagem de Língua Portuguesa e Matemática visando, sobretudo, elevar os dados do Índice de Desenvolvimento da Educação Básica (IDEB). Construir uma escola mais justa, mais democrática, com papel socializador efetivo, atenta aos novos saberes e questões do conhecimento, provavelmente incluirá a ampliação do seu tempo, mas não se reduza apenas a ela.

\section{REFERÊNCIAS}

ARROYO, M. 0 direito ao tempo de escola. Cadernos de Pesquisa, São Paulo, n. 65, p. 3-10, maio 1988.

ARROYO, M. 0 direito a tempos-espaços de um justo e digno viver. In: MOLL, J. et al. (org.). Caminhos da Educação Integral no Brasil: direito a outros tempos e espaços educativos. Porto Alegre: Penso, 2012.

BRASIL. Constituição. República Federativa do Brasil de 1988. Brasilia, DF: Senado, 5 out. 1988.

BRASIL. Decreto n. 6.094, de 24 de abril de 2007. Dispõe sobre a implementação do Plano de Metas Compromisso Todos pela Educação. Diário Oficial da União, Brasília, DF, 25 abr. 2007a. Disponível em: http://www.planalto.gov.br/ccivil_03/_ato2007-2010/2007/decreto/d6094.htm. Acesso em: 30 abr. 2018.

BRASIL. Decreto n. 7.083, de 27 de janeiro de 2010. Dispõe sobre o Programa Mais Educação. Diário Oficial da União, Brasilia, DF, 28 jan. 2010a. Disponível em: http://www.planalto.gov.br/ccivil_03/_ ato2007-2010/2010/decreto/d7083.htm. Acesso em: 10 set. 2018.

BRASIL. Lei n. 9.394, de 20 de dezembro de 1996. Estabelece as diretrizes e bases da educação nacional. Diário Oficial da União, Brasília, DF, 21 dez. 1996. Disponível em: http://www.planalto.gov.br/ ccivil_03/leis/L9394.htm. Acesso em: 10 ago. 2018. 
BRASIL. Lei n. 10.172, de 09 de janeiro de 2001. Aprova o Plano Nacional de Educação e dá outras providências. Diário Oficial da União, Brasília, 10 jan. 2001. Disponivel em: http://www.planalto.gov.br/ ccivil_03/LEIS/LEIS_2001/L10172.htm. Acesso em: 10 ago. 2018.

BRASIL. Lei n. 11.494, de 20 de junho de 2007. Regulamenta o Fundo de Manutenção e Desenvolvimento da Educação Básica e de Valorização dos Profissionais da Educação - FUNDEB. Diário Oficial da União, Brasilia, DF, 21 jun. 2007b. Disponível em: http://www.planalto.gov.br/ccivil_03/_Ato2007-2010/2007/ Lei/L11494.htm. Acesso em: 30 abr. 2018.

BRASIL. Ministério da Educação. Fundo Nacional de Desenvolvimento da Educação. Resolução no 17, de 22 de dezembro de 2017. Destina recursos financeiros ao Programa Novo Mais Educação. Brasília: DF, 2017a. Disponivel em: http://www.imprensanacional.gov.br/web/guest/consulta. Acesso em: 19 mai. 2018.

BRASIL. Ministério da Educação. Secretaria de Educação Continuada, Alfabetização e Diversidade. Programa Mais Educação: passo a passo. Brasília, DF, 2013. Disponível em: http://portal.mec.gov.br/ dmdocuments/passoapasso_maiseducacao.pdf. Acesso em: 01 jan. 2018.

BRASIL. Portaria n. 1.144, de 10 outubro de 2016. Institui o Programa Novo Mais Educação, que visa melhorar a aprendizagem em língua portuguesa e matemática no ensino fundamental. Diário Oficial da União, Brasília, n. 196, 11 out. 2016a. Seção 1, p. 23.

BRASIL. Portaria Normativa Interministerial n. 17, de 24 de abril de 2007. Institui o Programa Mais Educação. Diário Oficial da União, Brasília, DF, 26 abr. 2007c. Disponível em: http://portal.mec.gov.br/ arquivos/pdf/mais_educacao.pdf. Acesso em: 30 abr. 2018.

BRASIL. Programa Novo Mais Educação: Caderno de Orientações Pedagógicas - Versão I. Brasilia, 2017b. Disponivel em: http://portal.mec.gov.br/docman/agosto-2017-pdf/70831-pnme-caderno-de-orientacoes-pedagogicas-pdf/file. Acesso em: 01 jan. 2018.

CARDOSO, C. A. Q. Programa Novo Mais Educação (2016) e sua concepção de educação em tempo integral. 2018. 163 f. Dissertação (Mestrado em Gestão e Currículo da Educação Básica) - Universidade Federal do Pará, Belém, PA, 2018.

CAVALIERE, A. M. Entre o pioneirismo e o impasse: a reforma paulista de 1920. Educação e Pesquisa, São Paulo, v. 29, n. 1, p. 27-44, jan./jun. 2003.

CAVALIERE, A. M. Escolas de tempo integral versus alunos em tempo integral. Em Aberto, Brasília, DF, p. 51-63, abr. 2009.

COELHO, L. M. C. C. História(s) da educação integral. Em Aberto, Brasília, DF, v. 22, n. 80, p. 83-96, abr. 2009. 
DUTRA, T.; MOLL, J. A educação integral no Brasil: uma análise histórico-sociológica. Instituto Federal de Mato Grosso Campus Confresa. Revista Prática Docente, Mato Grosso, v. 3, n. 2, p. 813-829, jul./dez. 2018.

FUNDAÇÃO ITAÚ SOCIAL. 0 Programa Mais Educação - Ministério da Educação. Relatório de Avaliação Econômica e Estudos qualitativos. Avaliação econômica de projetos sociais. São Paulo: Fundação Itaú Social, 2015. Disponivel em: http://www.redeitausocialdeavaliacao.org.br/wp-content/uploads/2015/11/ relat_Mais_Educa\%C3\%A7\%C3\%A3o_COMPLET0_20151118.pdf. Acesso em: 1 set. 2016.

GADOTTI, M. Educação Integral no Brasil: inovações em processo. São Paulo: Editora e Livraria Instituto Paulo Freire, 2009.

INSTITUTO NACIONAL DE ESTUDOS E PESQUISAS EDUCACIONAIS ANISIO TEIXEIRA. Relatório do $3^{\circ}$ ciclo de monitoramento das metas do Plano Nacional de Educação - 2020: sumário executivo. Brasília, DF: INEP, 2020.

MENDES, G. M. L.; SEEMANN, V. C. LDB e ampliação da jornada: uma abordagem do ciclo de política. Revista Retratos da Escola, Brasilia, DF, v. 10, n. 19, p. 519-532, jul./dez. 2016. Disponível em: http:// retratosdaescola.emnuvens.com.br/rde/article/view/634. Acesso em: 20 nov. 2018.

MENDONÇA, P. M. 0 direito à educação em questão: as tensões e disputas no interior do Programa Mais Educação. 2017. Tese (Doutorado em Educação) - Programa de Pós-graduação em Educação, Universidade Federal de Minas Gerais, Belo Horizonte, 2017.

MÓL, S. C.; MACIEL, C. L. A.; MARTINS, F. S.a. Educação integral e(m) tempo integral, o Programa "Novo" Mais Educação e sua concepção de formação humana. In: REUNIÃO NACIONAL DA ANPED, 38., 2017, São Luís. Anais [...] São Luís: Universidade Federal do Maranhão, 1-5 out. 2017.

MOLL, J. A agenda da educação integral: compromissos para sua consolidação como política pública. In: MOLL, J et al. (org.). Caminhos da educação integral no Brasil: direito a outros tempos e espaços educativos. Porto Alegre: Penso, 2012.

MOLL, J. Meta 6: educação integral. In: OLIVEIRA, J. F.; GOUVEIA, A. B.; ARAÚJO, H. (org.). Caderno de Debates para avaliação das metas do Plano Nacional de Educação PNE 2014-2024. Brasília, DF: ANPAE, 2018.

OLIVEIRA, D. A. Política educativa, crise da escola e a promoção de justiça social. In: FERREIRA, E. B.; OLIVEIRA, D. A. (org.). Crise da escola e políticas educativas. Belo Horizonte: Autêntica Editora. 2009a.

OLIVEIRA, J. F. A função social da educação e da escola pública: tensões, desafios e perspectivas. In: FERREIRA, E. B.; OLIVEIRA, D. A. (org.). Crise da escola e políticas educativas. Belo Horizonte: Autêntica Editora. 2009b. 
PASSOS, E. B. Os desafios da gestão escolar na implementação do Programa Novo Mais Educação. Dissertação (Mestrado em Currículo e Gestão da Escola Básica) - Programa de Pós-Graduação em Currículo e Gestão da Escola Básica, Núcleo de Estudos Transdisciplinares em Educação Básica, Universidade Federal do Pará, Belém, 2020.

PERUZZO, V. Educação lem tempol integral: a contribuição do Programa Mais Educação - PME à comunidade escolar em um município da Serra Gaúcha/RS. 2018. Tese (Doutorado em Educação) - Programa de Pós-graduação em Educação, Universidade Federal do Rio Grande do Sul, Porto Alegre, 2018.

SANTOS, T. A. M. Série-Estudos. Periódico do Programa de Pós-Graduação em Educação da UCDB, Campo Grande, n. 29, p. 29-39, jan./jun. 2010.

SAQUELLI, G. F. Programa Mais Educação e o Novo Mais Educação: permanências e rupturas. 2018. Dissertação (Mestrado) - Universidade Estadual Paulista “Júlio de Mesquita Filho", Araraquara, 2018.

SILVA, A. T. A Escola Nova no interior do Ceará: desafios enfrentados pela reforma de Lourenço Filho na cidade de Sobral. Temporalidades, Belo Horizonte, v. 11, n. 2, maio/ago. 2019.

SILVA, G.; SILVA, A.V.; SANTOS, I. M. Gestão Escolar pós-LDB: o gerencialíssimo e a gestão democrática. Revista Retratos da Escola, Brasília, DF, v. 10, n. 19, p. 533-549, jul./dez. 2016. Disponível em: http// www.esforce.org.br. Acesso em: 20 ago. 2018.

Endereço para correspondência: Avenida Lourival Melo Mota, s/n, Tabuleiro do Martins, 57072-900, Maceió, Alagoas, Brasil; wiledna@uol.com.br 